\section{BMJ Open \\ Respiratory \\ Research}

\title{
Indwelling pleural catheters for non- malignant pleural effusions: report on a single centre's 10 years of experience
}

\author{
Nikolaj Frost (D) ,' Christoph Ruwwe-Glösenkamp, ${ }^{1}$ Matthias Raspe, ${ }^{1}$ \\ Martin Brünger (D) ,2 Bettina Temmesfeld-Wollbrück, ${ }^{1}$ Norbert Suttorp, ${ }^{1}$ \\ Martin Witzenrath ${ }^{1,3}$
}

To cite: Frost N, RuwweGlösenkamp C, Raspe M, et al. Indwelling pleural catheters for non-malignant pleural effusions: report on a single centre's 10 years of experience. BMJ Open Resp Res 2020;7:e000501. doi:10.1136/ bmjresp-2019-000501

Received 18 September 2019 Revised 18 November 2019 Accepted 3 January 2020

\section{Check for updates}

\section{(C) Author(s) (or their} employer(s)) 2020. Re-use permitted under CC BY-NC. No commercial re-use. See rights and permissions. Published by BMJ.

${ }^{1}$ Department of Infectious Diseases and Pulmonary Medicine, Charité Universitätsmedizin Berlin, corporate member of Freie Universität Berlin, HumboldtUniversität zu Berlin, and Berlin Institute of Health, Berlin, Germany

${ }^{2}$ Charité - Universitätsmedizin Berlin, corporate member of Freie Universität Berlin, Humboldt- Universität zu Berlin, and Berlin Institute of Health, Institute of Medical Sociology and Rehabilitation Science, Berlin, Germany, Charité Universitätsmedizin Berlin, Berlin, Germany ${ }^{3}$ Division of Pulmonary Inflammation, CharítéUniversitätsmedizin Berlin, Berlin, Germany

Correspondence to Dr Nikolaj Frost; nikolaj.frost@charite.de

\section{ABSTRACT}

Background Recurrent pleural effusion is a common cause of dyspnoea, cough and chest pain during the course of infectious pleurisy and non-malignant diseases like congestive heart failure (CHF) or liver cirrhosis with hepatic hydrothorax $(\mathrm{HH})$. With regard to the chronic character of the underlying diseases, indwelling pleural catheters (IPC) are increasingly used, not only assuring immediate symptom relief but also potentially leading to pleurodesis without sclerosing agents.

Patients and methods In this single-centre retrospective observational study, patient characteristics, procedural variables and outcome in patients with IPC in nonmalignant pleural effusion (NMPE) were evaluated and prognostic factors for pleurodesis were identified. Results From 2006 to 2017, 54 patients received 62 IPC, of whom $48.4 \%$ with $\mathrm{CHF}$ and $43.5 \%$ with $\mathrm{HH}$. The median length of insertion was 1.5 months (IQR 0.6-2.9 months), the median survival time after insertion 3.2 months (IQR 1.1-16.0). An adequate symptom relief was achieved in $93.2 \%$ with no need for subsequent interventions. In patients surviving $\geq 30$ days after IPC insertion, pleurodesis was observed in $45.9 \%$, being associated to age $(<55$ years, $p=0.02)$, the primary diagnosis $(p=0.03)$ and interventions for the underlying disease $(p<0.001)$. Complications occurred in $24.2 \%$ of all procedures $(n=15)$, the majority concerning mechanical obstructions $(n=10)$ and infections $(n=4)$. Patients with $\mathrm{HH}$ had an excess risk for complications (37.3\%).

Conclusion Efficacy in symptom relief and a generally manageable safety profile recommend IPC as a firstline treatment option in NMPE, where disease-specific treatments are exhausted. Caution is warranted in patients with $\mathrm{HH}$ due to an excess risk for complications.

\section{INTRODUCTION}

Chronic and recurrent pleural effusion (PE) is a common cause of dyspnoea, cough and chest pain affecting 1.5 million patients per year in the USA. ${ }^{1}$ The most common nonmalignant causes are infectious effusions, congestive heart failure (CHF), liver cirrhosis resulting in a hepatic hydrothorax $(\mathrm{HH})$ and renal failure. ${ }^{2}$ Although $70 \%-80 \%$ of all PEs are non-malignant (NMPE), treatment

\section{Key messages}

Can data on efficacy and safety of indwelling pleural catheters (IPC) in malignant pleural effusions be extrapolated on patients with non-malignant pleural effusions, where the data basis is weak?

Providing adequate symptom control in $>90 \%$ of patients with no need for subsequent interventions, IPC can be used as a first-line treatment option, where disease-specific treatments are exhausted.

We provide a comprehensive overview on patients with mainly chronic heart failure and hepatic hydrothorax, discuss predictors for pleurodesis and identify patients with liver cirrhosis to be at high risk for complications.

modalities in NMPE are widely adopted from the management of malignant PEs. ${ }^{1}$ Given a progressive deterioration of the underlying disease with effusion recurrences for years, therapeutic approaches should primarily focus on causative non-invasive procedures to minimise the risk for intervention-associated complications like pneumothorax, infections or bleeding. In malignant PE, a Cochrane network meta-analysis from 2016 considered indwelling pleural catheters (IPC) as alternative first-line therapeutic option besides talc pleurodesis (TP). ${ }^{3}$ The IPC is placed percutaneously and the procedure can be performed in an outpatient setting. ${ }^{4}$ Although the primary objective is symptom relief, pleurodesis in the absence of any sclerosing agent occurs in approximately $50 \% .^{5}$ Notably, for NMPE according recommendations are lacking as the respective data basis is weak.

The purpose of the present study was to add to the existing literature by evaluating clinical outcomes with IPC in NMPE in a single institution. Secondary goals were to assess survival outcomes in relation to patients and clinical variables and to determine predictors 
of pleurodesis, thus helping physicians to better guide clinical care.

\section{PATIENTS AND METHODS}

For this retrospective single-centre study, patients who received an IPC due to symptomatic recurrent NMPE treated at the Department of Infectious Diseases and Respiratory Medicine at the Charité - Universitätsmedizin Berlin were identified using a departmental database and the hospital's clinical reporting system. Data on patient's baseline demographics, underlying disease, quality of $\mathrm{PE}$, catheter laterality, pleurodesis, complications, time of catheter removal, need of subsequent procedures and day of last follow-up or death were collected.

All catheters (PleurX, CareFusion, San Diego, California, USA) were placed bedside in the endoscopy unit, ultrasound-guided and under local anaesthesia by a pulmonologist. Prophylactic peri-interventional antibiotics were not routinely administered. Outpatient drainage was performed by either the patients themselves or an ambulatory care service. According to the local standard of care, gravity bags were employed rather than vacuum bottles. They are generally used in Germany assuring slow and comfortable drainage. Patients were instructed to connect a gravity bag daily until the fluid accumulation decreased to less than $200 \mathrm{~mL}$ in 24 hours. Pleurodesis was assumed in the presence of less than $200 \mathrm{~mL}$ of PE per week and was defined as successful if no further intervention was needed after catheter removal. All complications were graded using the Clavien-Dindo classification for surgical complications. Thus, grade I/II complications only require pharmacological, grade III surgical, endoscopic or radiological interventions. Grade IV is lifethreatening, grade $\mathrm{V}$ denotes a procedure-related death. ${ }^{6}$

Follow-up data were obtained from the departmental clinical database and practitioners. Lost to follow-up was defined as missing data $\geq 30$ days between last documented visit and death. Overall survival was defined as the interval in months between IPC insertion and death.

\section{PATIENT AND PUBLIC INVOLVEMENT}

As this was a retrospective study, research was done without patient involvement. Patients were not invited to comment on the study design and were not consulted to develop patient relevant outcomes or interpret the results. Patients were not invited to contribute to the writing or editing of this document for readability or accuracy.

\section{STATISTICAL ANALYSIS}

Demographics and disease data were described and compared using the Pearson $\mathrm{X}^{2}$ test, Fisher's exact test or Mann-Whitney-U-test, according to the level of measurement. Binary logistic regression analyses were used to identify factors associated with pleurodesis. Survival was assessed with the Kaplan-Meier method. P values comparing survival curves were calculated with log-rank tests. All analyses were performed using IBM SPSS statistics V.24 (IBM). A p $<0.05$ (two tailed) was defined as statistically significant.

\section{RESULTS}

Between 2006 and 2017, 54 patients received 62 IPC. Thirty-two patients were male $(59.3 \%)$ and 22 female $(40.7 \%)$. Median age at time of catheter insertion was 68.5 years (range 32-95, IQR 56-76). The most frequent diagnoses were CHF $(\mathrm{n}=30,48.4 \%)$ and liver cirrhosis $(\mathrm{n}=27,43.5 \%)$. Recurrent postinfectious effusions were treated with an IPC in three patients. The remaining two cases were a chylothorax and one PE of unknown origin. All procedures were preceded by at least two thoracenteses or a chest tube before insertion of the IPC. Supply with an IPC following TP failure was performed in four patients $(6.5 \%)$. More catheters were placed right than left sided ( 62.9 vs $25.8 \%$ ), in $11.3 \%$ bilateral procedures were executed. All effusions due to heart failure and cirrhosis were transudates, but significant differences between those two entities in albumin/protein content and serum LDH were noted (albumin $14.1 \pm 5.9 \mathrm{~g}$ / $\mathrm{dL}$ vs $7.6 \pm 6.2 \mathrm{~g} / \mathrm{dL}, \mathrm{p}=0.001$; protein $25.2 \pm 10.1 \mathrm{~g} / \mathrm{dL}$ vs $14.6 \pm 10.3 \mathrm{~g} / \mathrm{dL}, \mathrm{p}<0.001$; $\mathrm{LDH} 124.3 \pm 58.2 \mathrm{U} / \mathrm{L}$ vs $93.1 \pm 38.6 \mathrm{U} / \mathrm{L}, \mathrm{p}=0.027)$. In contrast, all postinfectious effusions were exudates. All baseline demographics are shown in table 1.

\section{FOLLOW-UP}

Median follow-up for all patients was 3.2 months (range 5 days to 76.5 months, IQR $0.9-12.5$ ). At the time of data cut-off (27 March 2018), 10 patients were still alive (18.5\%), 43 had died (79.6\%), one was lost to follow-up $(1.9 \%)$. Considering that most IPCs in NMPE are used as palliative treatment for advanced disease states, survival after catheter insertion is limited. In the present investigation, $24.1 \%$ of patients died within 1 month postprocedure $(n=13)$. Nevertheless, the health status of eight patients significantly improved after IPC placement and they were thus able to receive further interventions for their underlying disease $(12.9 \%)$. Out of seven patients with $\mathrm{HH}$, one patient subsequently underwent liver transplantation, six patients received a transjugular intrahepatic portosystemic shunt (TIPS), one patient with CHF had a transcatheter aortic valve replacement. All procedures were performed within 1 month after IPC placement. Median catheter permanence was 1.5 months for all patients (range 5 days to 16.0 months, IQR $0.6-2.9$ ) and 2.1 months in those surviving at least 1 month (40 patients, 47 IPC, IQR 1.5-3.4, p<0.001).

\section{EFFICACY AND PLEURODESIS}

To determine the efficacy with regard to sufficient symptom relief, we investigated the need of subsequent invasive procedures. Follow-up data were available for 


\begin{tabular}{lll}
\hline Table 1 Baseline characteristics & & \\
\hline \multicolumn{1}{l}{ N } & $\%$ \\
\hline Total & 54 & \\
$\quad$ Male & 32 & 59.3 \\
\hline Female & 22 & 40.7 \\
\hline Age (years) & 68.5 & $32-95$ \\
\hline Underlying disease & & \\
\hline Heart failure & 30 & 48.4 \\
\hline Cirrhosis & 27 & 43.5 \\
\hline Other & 5 & 9.3 \\
\hline Postinfectious & 3 & 5.6 \\
\hline Para-pneumonic & 2 & 3.7 \\
\hline Postperitonitis & $*$ & 1.9 \\
\hline Chylothorax & $*$ & 1.9 \\
\hline PE of unknown origin & $*$ & 1.9 \\
\hline Catheters & & \\
\hline Total & 62 & \\
\hline Laterality & & \\
\hline Left & 16 & 25.8 \\
\hline Right & 39 & 62.9 \\
\hline Bilateral & 7 & 11.3 \\
\hline PE & & \\
\hline Transudate & 59 & 95.2 \\
\hline Exudate & 3 & 4.8 \\
\hline
\end{tabular}

*Values are given as 'median (range)'.

$P E$, pleural effusion.

59 procedures demonstrating no need for additional interventions in $93.2 \%(55 / 59)$. Thoracenteses or the insertion of a second chest tube after IPC removal were performed four times $(4 / 59,6.8 \%)$, of which three $(5.1 \%)$ and one $(1.7 \%)$ were interventions due to a preceding IPC-related complication or pleurodesis failure, respectively. Although pleurodesis is not the primary goal of IPC, it is associated with improved quality of life and therefore indicative of palliation. ${ }^{7}$ Pleurodesis was achieved in 39.0\% (23/59; no pleurodesis: $56.5 \%$, $35 / 59$; not reported: $6.8 \%, 4 / 59)$. All patients with postinfectious effusions developed pleurodesis, whereas rates in cardiogenic effusions and cirrhosis were considerably lower $(24.1 \%$ and $21.1 \%$, respectively, $\mathrm{p}=0.026)$. If further disease-specific interventions were performed, IPCs were able to be removed in $26.7 \%$ in heart failure (p NS) and $40.7 \%$ in $\mathrm{HH}$ ( $\mathrm{p}=0.009)$, representing either pleurodesis or cessation of pleural fluid accumulation. Median time to pleurodesis was 1.6 months (range 16 days to 3.5 months, IQR 0.9-3.2). To exclude the negative bias of patients not surviving long enough to develop pleurodesis, we further examined the subgroup of patients surviving $\geq 1$ month. Here, pleurodesis rate increased to $45.9 \%$ (17/37 IPC). Following pleurodesis, all catheters were removed soon (median 0 days, range 0 days to 1.2 months).

\section{PREDICTORS FOR PLEURODESIS}

In univariate logistic regression, age $<55$ years $(\mathrm{p}=0.02)$, survival of $\geq 1$ month after IPC insertion $(<0.001)$, the primary diagnosis $(\mathrm{p}=0.03)$ and interventions for the underlying disease $(p<0.001)$ were significantly correlated to pleurodesis. In multiple regression analysis, age $<55$ years $(\mathrm{p}=0.021$, HR $7.14,95 \%$ CI 1.35 to 33.3$)$ and interventions for the underlying disease $(\mathrm{p}=0.009$, HR 16.7, 95\% CI 2.08 to 99.8) remained predictive for pleurodesis. No associations were found for catheter permanence, laterality (left vs right, unilateral vs bilateral), composition of PE (albumin, protein, LDH) and complications (yes vs no). Excluding patients who had received disease-specific interventions, the primary diagnosis was also predictive for pleurodesis (postinfectious effusions vs other, $\mathrm{p}=0.028$, HR 17.33 , 95\% CI 1.35 to 222.16 ).

\section{COMPLICATIONS}

Complications occurred in $24.2 \%$ of all procedures affecting $20.4 \%$ of the patients ( 15 cases, 11 patients, all listed in table 2).

The complication rate was $16.7 \% \quad(n=5)$ in heart failure and $37.3 \% \quad(n=10)$ in cirrhosis $(\mathrm{p}=0.038)$. No complications were seen in postinfectious PE. The most common complications were malfunctions of the IPC $(66.7 \%, 10 / 15)$, followed by infections $(26.7 \%, 4 / 15)$. All dislodgements and infections except one occurred in patients with cirrhosis. One postinterventional bleeding was also seen in this group. Using the Clavien-Dindo classification, $86.7 \%(13 / 15)$ were graded as mild or moderate. Two fatal complications were seen in patients developing empyema with subsequent sepsis and multiorgan failure. Median time to complication was 19 days (range 1-446 days, IQR 10-61). A trend to an earlier onset was seen in cirrhosis (27.7 vs 122.4 days in heart failure, $\mathrm{p}=0.14$ ) and with mechanical complications (27.5 vs 146.5 days, $\mathrm{p}=0.075$ ). In general, catheters were removed after onset of complications $(86.7 \%, 13 / 15)$. This concerned all catheters with infections and $9 / 10$ IPC with mechanical complications. According to the Clavien-Dindo classification, removal is considered as an intervention and therefore classified as grade III. Microbiological cultures were positive in all empyema cases (one case each with coagulase-negative staphylococci, Klebsiella pneumoniae and Escherichia coli). One occlusion could be resolved using fibrinolytic agents, one bleeding in the subcutaneous tract in a patient with liver cirrhosis was stopped after local ingestion of epinephrine.

\section{SURVIVAL WITH IPC}

For the entire cohort, median survival after catheter insertion was 3.2 months (IQR 1.1-16.0, 95\% CI 1.5 to 4.9). No significant differences were observed for the underlying disease with 3.1 months in heart failure (IQR $1.1-15.3,95 \%$ CI 0.9 to 5.3 ), 4.0 months in cirrhosis (IQR 0.6-42.7, 95\% CI 1.8 to 6.2 ) and 3.2 months in the 
Table 2 Complications

\begin{tabular}{|c|c|c|c|c|c|c|c|}
\hline & $\mathbf{N}$ & $\begin{array}{l}\% \\
\text { (of } \\
\text { complications) }\end{array}$ & $\begin{array}{l}\% \\
\text { (of } \\
\text { procedures) }\end{array}$ & $\begin{array}{l}\text { Grade II } \\
\text { (n) }\end{array}$ & $\begin{array}{l}\text { Grade } \\
\text { III } \\
\text { (n) }\end{array}$ & $\begin{array}{l}\text { Grade V } \\
\text { (n) }\end{array}$ & $\begin{array}{l}\text { Time to } \\
\text { complication } \\
\text { (median, } \\
\text { range) }\end{array}$ \\
\hline Total & 15 & 100.0 & 24.2 & 2 & 11 & 2 & $19(1-446)$ \\
\hline \multicolumn{8}{|l|}{ Aetiology } \\
\hline Infections & 4 & 26.7 & 6.5 & - & 2 & 2 & \\
\hline Local infection (cellulitis/exit site) & 1 & 6.7 & 1.6 & - & 1 & - & \\
\hline Deep infection (empyema) & 3 & 20.0 & 4.8 & - & 1 & 2 & \\
\hline Catheter malfunction & 10 & 66.7 & 16.1 & 1 & 9 & - & \\
\hline Occlusion/mechanical obstruction & 2 & 13.3 & 3.2 & 1 & 1 & - & \\
\hline Dislodgement & 5 & 33.3 & 8.1 & - & 5 & - & \\
\hline Leakage & 3 & 20.0 & 4.8 & - & 3 & - & \\
\hline Bleeding & 1 & 6.7 & 1.6 & 1 & - & - & \\
\hline Catheter removed & 13 & 86.7 & 21.0 & & & & \\
\hline
\end{tabular}

remaining diseases (IQR 1.8-19.9, 95\% CI 0.3 to 6.1 , $\mathrm{p}=0.58)$.

\section{DISCUSSION}

Recurrent PE is associated with a high disease burden in many non-malignant diseases, often indicating the final common pathway for these patients without leaving a causative treatment option. We here have reported on a large single-centre experience on clinical characteristics and outcome of patients with IPC in NMPE. Although NMPEs are more common than MPE, evidence on IPC in NMPE is limited. In a meta-analysis including 325 patients from 13 studies, the median number of patients (and catheters) per study was only 23 (range $5-57)^{5}$ and thus lower than the number of patients in studies with MPE (median 55, range 5-263). ${ }^{8}$ The patient distribution in our cohort underlines the predominance of patients with $\mathrm{CHF}$ and $\mathrm{HH}$ with the use of IPCs for refractory NMPE despite optimal medical therapy and is in line with a meta-analysis by Patil et al. ${ }^{5}$

The primary goal of symptom control and satisfying palliation without need for subsequent procedures with IPC can be achieved in over $80 \% .^{9}$ Patient satisfaction is high, not least because readmission rates substantially decrease after catheter insertion. ${ }^{10-12}$ Furthermore, in a study comparing IPC and TP in a propensitymatched design, not only the time spent in hospital peri-interventionally was shorter with IPC, but also readmission rates the year after were lower. ${ }^{13}$ Due to the retrospective character of our study, palliation could only be assessed in an indirect manner focusing on the need of additional (invasive) procedures like thoracenteses or (second) chest tubes. In our study, additional procedures were necessary in $6.8 \%$ of all catheters, thereby underlining the long-term efficacy of the procedure.

Pleurodesis is a convenient side effect of IPC and occurs in approximately half of the patients irrespective of the underlying disease. ${ }^{5}$ In our cohort, the general pleurodesis rate was $39.0 \%$, but with regard to a median time to pleurodesis of 1 month, rates increased to $45.9 \%$ in those surviving at least this period. As all patients with infectious pleurisy developed pleurodesis, the rates were substantially driven by this group and were considerably lower in CHF $(24.1 \%)$ and $\mathrm{HH}(21.1 \%)$. The identified predictors for pleurodesis included the primary diagnosis and the possibility for an interventional approach. Thus, in patients with HH, TIPSS implantation and liver transplantation augmented pleurodesis rates from $21.1 \%$ to $40.7 \%$. Li et al recently reported an overall pleurodesis rate of $74 \%$ using IPC in NMPE. ${ }^{14}$ Although results were influenced by high pleurodesis rates in inflammatory pleurisy and parapneumonic effusions, the reported pleurodesis rates in heart and liver failure also were substantially higher as compared with our study. Selection bias could explain this gap, but procedure-related differences like the drainage interval applied might also play a role, as clearly shown in malignant PE. ${ }^{15} 16$ Interestingly, despite using a daily drainage interval in our study, the pleurodesis rate was inferior to the investigation from Li et al using a 2-day regimen. So, to elucidate the value of the drainage strategy in NMPE, further prospective studies are needed. The exact way how IPC lead to pleurodesis is unclear, however, mechanical irritation causing local inflammation likely contributes to it. ${ }^{17}$ As the inflammatory response diminishes with increasing age and is altered in liver cirrhosis, older patients and those with an $\mathrm{HH}^{18}$ might experience pleurodesis less often, as shown in the current study. A general inflammatory condition in infectious pleurisy may also provide the rationale for the high pleurodesis rates observed. ${ }^{19}$

In two meta-analyses, (median) rates of periprocedural and long-time complications with IPC were slightly higher in NMPE than in MPE $\left(17.2^{5}\right.$ vs $\left.12.5 \%\right){ }^{8}$ As most studies in NMPE did not report the catheter permanence, one 
can refer to the longer time to pleurodesis in NMPE (and thus longer catheter permanence) as a surrogate for this period (36 vs 110 days $^{20}$ ). Thus, complication rates in both entities seem quite comparable. The most common complications are infections and mechanical catheter problems. Rates of pleural infections are generally very low ranging below $6 \%,{ }^{10-13} 1820$ except for patients with liver cirrhosis and $\mathrm{HH}$, where rates up to $16.7 \%$ have been described..$^{21}$ As deep infections usually occur not earlier than 6 weeks after the procedure, ingestion of bacteria during catheter insertion is unlikely. The higher overall complication rate in our study of $24.2 \%$ compared with $17.2 \%$ in the meta-analysis by Patil et a $\tilde{p}$ might be related to the longer observation period in our study. Furthermore, $66.7 \%$ of all complications occurred within the first 4 years. In line with the literature, we observed an excess risk for complications in patients with $\mathrm{HH}$, comprising both mechanical and infectious complications. Thus, the use of an IPC in this setting requires close monitoring, should be embedded in a multidisciplinary approach and requires preventive measures such as patient education in the proper use of the catheter.

Due to the retrospective character, the present study has several limitations. On the one hand, the data provide a deep insight into the management and follow-up of patients with IPC in NMPE, even though our data set is dominated by patients with $\mathrm{CHF}$ and $\mathrm{HH}$ and lacks patients with, for example, chronic renal failure or rheumatic diseases. On the other hand, providing a patient with an IPC or not is subject to the physician's decision and thereby source of a selection bias. Symptom-related data were not collected regularly; thus, symptom relief could only be assessed indirectly with regard to the need of subsequent invasive procedures. Moreover, the estimation of procedure-related complications may be too low as some events may have been undocumented, especially in those lost to follow-up. Finally, in patients who have received an intervention for the underlying disease, it is difficult to differentiate between real pleurodesis and only a cessation of effusion accumulation, if the organ function of these patients has conditionally improved. Nevertheless, the current study contributes to the growing body of evidence of IPC as a safe and feasible treatment option also in the management of NMPE, with the exception of patients with $\mathrm{HH}$, for whom the use of an IPC needs critical consideration due to high complication rates.

Contributors NF designed the study and assembled the data set. NF and MB analysed the data. All authors contributed to the interpretation of the results. NF and MB organised the drafting of the manuscript. All authors contributed to the writing of the manuscript and approved the final version.

Funding We acknowledge support from the German Research Foundation (DFG) and the Open Access Publication Funds of Charité - Universitätsmedizin Berlin

Competing interests None declared.

Patient consent for publication Not required.

Ethics approval Approval for the study was obtained from the Charite Universitätsmedizin Berlin ethics committee (EA2/037/18).
Provenance and peer review Not commissioned; externally peer reviewed.

Data availability statement Data are available on reasonable request. Deidentified participant data are available on reasonable request as an SPSS file from the corresponding author.

Open access This is an open access article distributed in accordance with the Creative Commons Attribution Non Commercial (CC BY-NC 4.0) license, which permits others to distribute, remix, adapt, build upon this work non-commercially, and license their derivative works on different terms, provided the original work is properly cited, appropriate credit is given, any changes made indicated, and the use is non-commercial. See: http://creativecommons.org/licenses/by-nc/4.0/.

ORCID iDs

Nikolaj Frost http://orcid.org/0000-0001-7452-7129

Martin Brünger http://orcid.org/0000-0001-5998-7143

\section{REFERENCES}

1 Light RW. Pleural effusions. Med Clin North Am 2011;95:1055-70.

2 Bintcliffe OJ, Lee GYC, Rahman NM, et al. The management of benign non-infective pleural effusions. Eur Respir Rev 2016;25:303-16.

3 Clive $\mathrm{AO}$, Jones $\mathrm{HE}$, Bhatnagar $\mathrm{R}$, et al. Interventions for the management of malignant pleural effusions: a network metaanalysis. Cochrane Database Syst Rev 2016;5:CD010529.

4 Putnam JB, Walsh GL, Swisher SG, et al. Outpatient management of malignant pleural effusion by a chronic indwelling pleural catheter. Ann Thorac Surg 2000;69:369-75.

5 Patil M, Dhillon SS, Attwood K, et al. Management of benign pleural effusions using indwelling pleural catheters: a systematic review and meta-analysis. Chest 2017;151:626-35.

6 Dindo D, Demartines N, Clavien P-A. Classification of surgical complications: a new proposal with evaluation in a cohort of 6336 patients and results of a survey. Ann Surg 2004;240:205-13.

7 Fortin M, Tremblay A. Pleural controversies: indwelling pleural catheter vs. pleurodesis for malignant pleural effusions. J Thorac Dis 2015;7:1052-7.

8 Van Meter MEM, McKee KY, Kohlwes RJ. Efficacy and safety of tunneled pleural catheters in adults with malignant pleural effusions: a systematic review. J Gen Intern Med 2011;26:70-6.

9 Chambers DM, Abaid B, Gauhar U. Indwelling pleural catheters for nonmalignant effusions: evidence-based answers to clinical concerns. Am J Med Sci 2017;354:230-5.

10 Krishnan M, Cheriyath P, Wert Y, et al. The Untapped Potential of Tunneled Pleural Catheters. Ann Thorac Surg 2015;100:2055-7.

11 Potechin R, Amjadi K, Srour N. Indwelling pleural catheters for pleural effusions associated with end-stage renal disease: a case series. Ther Adv Respir Dis 2015;9:22-7.

12 Srour N, Potechin R, Amjadi K. Use of indwelling pleural catheters for cardiogenic pleural effusions. Chest 2013;144:1603-8.

13 Freeman RK, Ascioti AJ, Dake M, et al. A propensity-matched comparison of pleurodesis or tunneled pleural catheter for heart failure patients with recurrent pleural effusion. Ann Thorac Surg 2014;97:1872-7.

14 Li P, Hosseini S, Zhang T, et al. Clinical predictors of successful and earlier removal of indwelling pleural catheters in benign pleural effusions. Respiration 2019;98:239-45.

15 Wahidi MM, Reddy C, Yarmus L, et al. Randomized trial of pleural fluid drainage frequency in patients with malignant pleural effusions. The ASAP trial. Am J Respir Crit Care Med 2017;195:1050-7.

16 Muruganandan S, Azzopardi M, Fitzgerald DB, et al. Aggressive versus symptom-guided drainage of malignant pleural effusion via indwelling pleural catheters (AMPLE-2): an open-label randomised trial. Lancet Respir Med 2018;6:671-80.

17 Mercer RM, Hassan M, Rahman NM. The role of pleurodesis in respiratory diseases. Expert Rev Respir Med 2018;12:323-34.

18 Bhatnagar R, Reid ED, Corcoran JP, et al. Indwelling pleural catheters for non-malignant effusions: a multicentre review of practice: Table 1. Thorax 2014;69:959-61.

19 Fysh ETH, Tremblay A, Feller-Kopman D, et al. Clinical outcomes of indwelling pleural catheter-related pleural infections: an international multicenter study. Chest 2013;144:1597-602.

20 Chalhoub M, Harris K, Castellano M, et al. The use of the PleurX catheter in the management of non-malignant pleural effusions. Chron Respir Dis 2011;8:185-91.

21 Chen A, Massoni J, Jung D, et al. Indwelling tunneled pleural catheters for the management of hepatic hydrothorax. A pilot study. Ann Am Thorac Soc 2016;13:862-6. 